\title{
A Novel Clinical Pharmacy Management System in Improving the Rational Drug Use
}

\author{
Xianhua Ren*, Yi Wang, Ruilian Ma \\ Department of Pharmacy, Affiliated Hospital of Inner Mongolia Medical University, Hohhot, P. R. China
}

Email address:

renxianhua237@163.com (Xianhua Ren)

To cite this article:

Xianhua Ren, Yi Wang, Ruilian Ma. A Novel Clinical Pharmacy Management System in Improving the Rational Drug Use. Clinical Medicine Research. Vol. 4, No. 6, 2015, pp. 229-233. doi: 10.11648/j.cmr.20150406.20

\begin{abstract}
A clinical pharmacy management system (CPMS) software developed by our hospital has been described and utilized to provide drug information services, promote the rational drug use, improve the efficiency of clinical pharmacists, and carry out investigations on the counting of large sample cases taking the example of the urology department. The efficiency, normalization and accuracy of the prescription evaluations by the clinical pharmacists were improved, the quality and passing rates of the evaluation results were ensured, and the rational drug use and drug information services in the urology department of our hospital were also improved. The system could eventually promote the clinical drug information services in the whole hospital onto a new level.
\end{abstract}

Keywords: Pharmacy Service, Clinical Pharmacist, Urology, Clean Surgery, Prescription Evaluation

\section{Introduction}

With the urgent need of national health reform and development for information construction and the rapid development of computer communication technology, medical information processing in domestic hospitals has changed significantly. Hospital Information System (HIS) has been applied in many hospitals, which is utilized to store, process and manage the massive medical data by computers, and the essential part of HIS is the pharmacy management system [1]. Currently, the pharmacy management system used in our hospital is developed mainly concerning the guarantee of drug supply, in which the core part consists of the input, selling and storage of drugs, i.e. the management of logistics and the cash flow. This part will realize electronic accounting by the drug accountants. However, considering that clinical pharmacists begin to emphasize on the patient-centered pharmacy services instead of drug supplies [2,3], current HIS should be replaced by more advanced computer software systems $[4,5]$.

The clinical pharmacists in our hospital are mainly in charge of close cooperation with the clinicians to grasp the overall conditions of the patients and completion of their corresponding medical records. Inpatient and outpatient medical orders are selected monthly for analysis and evaluation, and prescription evaluations should also be completed and submitted [6]. Besides, the obtained results should be submitted annually according to the relative requirements in "Notification on the establishment of clinical use of antibiotics and bacterial resistance monitoring network" ("Except for the establishment of national 'clinical use of antibiotics monitoring network' and 'bacterial resistance monitoring network', corresponding monitoring should also be gradually carried out in appropriate areas and units.").

However, the procedure mentioned above is laborious. Taking the prescription evaluations as the example, 100 prescriptions and 30 medical orders should be selected equally, and the corresponding paper medical records are needed to evaluate the underlying information. Besides, filling out the resulting forms will also cost plenty of time and efforts. Completing the number of basic drugs is especially time-consuming due to the requirement of checking each drug information in every prescription. Meanwhile, completing the investigation forms of the use of antibiotics is sophisticated because every item should be referred to the whole medical records. In addition, samples consisting of the selected 100 prescriptions, 30 medical orders and 120 medical records are still insufficient, and the data obtained by different samplers will also differ greatly in the same period. Therefore, the resulting data will not comprehensively reflect the overall conditions of the prescriptions and antimicrobial drug use.

As a result, the pharmacy department of our hospital has been principally focusing on the effective improvement of 
work efficiency as well as the systematized, standardized and scientized management. Taking into consideration of the above demands, an electronic information product, i.e. the clinical pharmacy management system (CPMS), which is more suitable for the clinical pharmacists, has been developed by our hospital in 2010 and began to be used since January 1st, 2011. The system is connected to HIS of our hospital, which computerizes the medical information and further customizes the paper prescriptions and medical orders according to "Prescription Administrative Policy" and the relevant laws and regulations. Besides, the system replaces the work of the clinical pharmacists including manual samplings, prescription (medical orders) evaluations and reports of antibiotics. The system has been tested in our hospital for a period of time and demonstrated to perform well.

The main advantages of CPMS include: 1. Real-time monitoring the prescriptions or medical orders, which will timely warn the irrational drug use and thus greatly increase the passing rates of the prescriptions. 2. Obeying the relevant provisions of "Prescription Administrative Policy" of WHO ("Medial institutions ought to establish the prescription evaluation systems, complete the evaluation forms, monitor the implementation of prescriptions, warn the abnormal conditions, register and notify the irrational prescriptions, and timely intervene the irrational drug use") [7, 8]. 3. Realizing the precise and detailed screening and counting of large sample cases to meet the requirements of clinical pharmacy research. Taking the prescription evaluations in the urology department as the example, prescription passing rates, common use of antibiotics, and use of antibiotics in the aseptic operations in the urology department in our hospital in 2010 and 2011 were counted and compared, and the results before and after utilizing CPMS were summarized.

\section{Materials and Methods}

\subsection{Prescriptions and Patients}

11426 outpatient and 1216 inpatient prescriptions in the urology department were counted, in which 219 patients with Class 1 incisions were at the mean age of $41 \pm 9$ years old. Patients in all the cases were male.

\subsection{Required Information}

Information of patients: hospital (outpatient) numbers, names, gender, ages, weights, inpatient days (surgery names and time were also recorded for the patients in the urology department with Class 1 incisions) [9].

Information of drug use: number of drugs, number of antibiotics, usage, dosage and utilization time of antibiotics.

Evaluation criteria: "Guidelines for Clinical Use of Antibacterial Agents" [2004] No. 285 issued by China's Ministry of Health (abbreviated as guidelines below), notification on the clinical use of antibiotics issued by Ministry of Health [2009] No. 38, relevant references and judgments on the reasonable use of medicine instructions. The main content included: openness of prescription diagnoses, symptomatic treatments, correct drug use for special groups (elderly, children or patients with special diseases), correct prophylactic drug use for inpatients after aseptic operations, etc [10].

Statistical software and methods: CPMS was utilized to screen the large sample cases of medical records.

\section{Results}

\subsection{Review Results of the Large Sample Prescriptions After Utilizing CPMS}

After utilizing CPMS in our hospital since January 1st, 2011, large samples of all the outpatient and inpatient prescriptions have been successfully screened. Passing rates of the outpatient prescriptions gradually increased from $47.5 \%$ in January to $90.1 \%$ in December within one year, and those of the inpatient prescriptions also increased from $66.5 \%$ to $91.7 \%$. The results are listed in Table 1 .

Table 1. Passing rates of the prescriptions in the urology department in 2011.

\begin{tabular}{|c|c|c|c|c|c|c|c|c|c|c|c|c|}
\hline \multirow{2}{*}{ Prescription source } & \multicolumn{2}{|l|}{ Jan } & \multicolumn{2}{|l|}{ Feb } & \multicolumn{2}{|l|}{ Mar } & \multicolumn{2}{|l|}{ Apr } & \multicolumn{2}{|l|}{ May } & \multicolumn{2}{|l|}{ Jun } \\
\hline & Out $^{\mathrm{a}}$ & $\operatorname{In}^{\mathrm{b}}$ & Out & In & Out & In & Out & In & Out & In & Out & In \\
\hline Qualified prescriptions & 463 & 82 & 532 & 74 & 584 & 64 & 559 & 75 & 597 & 75 & 650 & 66 \\
\hline Total prescriptions & 975 & 123 & 984 & 108 & 1021 & 96 & 926 & 102 & 935 & 101 & 914 & 89 \\
\hline Qualified rate (\%) & 47.5 & 66.5 & 54.1 & 68.4 & 57.2 & 66.7 & 60.4 & 73.5 & 63.8 & 74.5 & 71.1 & 74.2 \\
\hline
\end{tabular}

Table 1. Continue.

\begin{tabular}{|c|c|c|c|c|c|c|c|c|c|c|c|c|}
\hline \multirow{2}{*}{ Prescription source } & \multicolumn{2}{|l|}{ Jul } & \multicolumn{2}{|l|}{ Aug } & \multicolumn{2}{|l|}{ Sep } & \multicolumn{2}{|l|}{ Oct } & \multicolumn{2}{|l|}{ Nov } & \multicolumn{2}{|l|}{ Dec } \\
\hline & Out & In & Out & In & Out & In & Out & In & Out & In & Out & In \\
\hline Qualified prescriptions & 745 & 75 & 803 & 77 & 810 & 82 & 851 & 87 & 876 & 97 & 842 & 94 \\
\hline Total prescriptions & 933 & 94 & 957 & 92 & 926 & 97 & 948 & 98 & 972 & 114 & 935 & 102 \\
\hline Qualified rate $(\%)$ & 79.8 & 80.1 & 83.9 & 83.4 & 87.5 & 84.5 & 89.8 & 88.4 & 90.1 & 84.7 & 90.1 & 91.7 \\
\hline
\end{tabular}

${ }^{\mathrm{a}}$ Abbreviation of outpatient; ${ }^{\mathrm{b}}$ Abbreviation of inpatient 


\subsection{Use of Antibiotics for the Outpatients and Inpatients in the Urology Department in 2011}

After the prescriptions being intervened by CPMS in 2011, the use of antibiotics for the outpatients in the urology department apparently fell from $31.2 \%$ in January to $18.1 \%$ in December, and that of the inpatients decreased from $70.1 \%$ to 32.4. The results are summarized in Table 2 .

Table 2. Treatment proportion of antibiotics in 2011 (\%).

\begin{tabular}{lllllllllllll}
\hline & Jan & Feb & Mar & Apr & May & Jun & Jul & Aug & Sep & Oct & Nov & Dec \\
\hline Inpatient & 70.1 & 66.8 & 64.2 & 63.4 & 60.1 & 55.2 & 47.9 & 45.2 & 44.1 & 39.3 & 38.1 & 32.4 \\
Outpatient & 31.2 & 30.4 & 25.5 & 21.7 & 20.2 & 19.7 & 19.8 & 18.7 & 18.9 & 19.0 & 18.5 & 18.1 \\
\hline
\end{tabular}

\subsection{Use of Antibiotics in Aseptic Operations in 2011}

CPMS was also utilized to intervene the drug use in the aseptic operations of urology department. The use of surgical antibiotics significantly decreased from $89.8 \%$ in January to $46.1 \%$ in December in 2011 , and the results are shown in Table 3 .

Table 3. Use of prophylactic antibiotics for aseptic operations in 2011.

\begin{tabular}{|c|c|c|c|c|c|c|c|c|c|c|c|c|}
\hline & Jan & Feb & Mar & Apr & May & Jun & Jul & Aug & Sep & Oct & Nov & Dec \\
\hline Treatment proportion of antibiotics $(\%)$ & 89.8 & 81.2 & 80.3 & 77.5 & 71.4 & 68.7 & 65.5 & 60.1 & 57.4 & 54.1 & 48.7 & 46.1 \\
\hline
\end{tabular}

\subsection{Intensity of Antibiotics for the Inpatients in the Urology Department in 2011}

The use of antibiotics in the urology department has been strictly restricted by CPMS since January 2011, which significantly reduced the total amount of antibiotics and the defined daily dose of antibiotics for the inpatients (DDD) from 134.7 in January to 38.4 in December, and the results are shown in Table 4.

Table 4. Defined daily dose of antibiotics for the inpatients in the urology department in 2011.

\begin{tabular}{|c|c|c|c|c|c|c|c|c|c|c|c|c|}
\hline & Jan & Feb & Mar & Apr & May & Jun & Jul & Aug & Sep & Oct & Nov & Dec \\
\hline DDD & 134.7 & 104.2 & 96.5 & 90.1 & 84.7 & 83.1 & 79.4 & 72.2 & 63.9 & 52.8 & 39.9 & 38.4 \\
\hline
\end{tabular}

\subsection{Passing Rates of the Prescriptions of Our Hospital Before and After Utilizing the Clinical Pharmacy Management System}

Drug use passing rates of the outpatient and inpatient cases before and after utilizing CPMS (2010 and 2011) were counted and compared. Because the prescriptions of our hospital were manually counted with relatively low work efficiency in 2010, only 100 outpatient prescriptions and 30 inpatient medical orders were selected, which were also utilized in 2011. The prescription passing rates in the urology department were improved to diverse extents after employing CPMS since January 2011, and the results are listed in Table 5.

Table 5. Passing rates of outpatients and inpatient prescriptions in the urology department in 2010 and 2011 (The number of prescriptions utilized in 2011 was the same as that in 2010, i.e. 100 outpatient prescriptions, 30 inpatient medical orders).

\begin{tabular}{|c|c|c|c|c|c|c|c|c|c|c|c|c|}
\hline \multirow{2}{*}{ Time } & \multicolumn{2}{|l|}{ Jan } & \multicolumn{2}{|l|}{ Feb } & \multicolumn{2}{|l|}{ Mar } & \multicolumn{2}{|l|}{ Apr } & \multicolumn{2}{|l|}{ May } & \multicolumn{2}{|l|}{ Jun } \\
\hline & 2010 & 2011 & 2010 & 2011 & 2010 & 2011 & 2010 & 2011 & 2010 & 2011 & 2010 & 2011 \\
\hline Qualified rate (Outpatient \%) & 63.3 & 65.4 & 64.7 & 71.1 & 60.4 & 72.4 & 62.4 & 74.9 & 59.8 & 78.6 & 58.7 & 77.9 \\
\hline Qualified rate (Inpatient \%) & 45.1 & 49.6 & 42.1 & 58.1 & 41.8 & 57.4 & 40.3 & 64.6 & 43.5 & 66.2 & 47.1 & 70.8 \\
\hline
\end{tabular}

Table 5. Continue.

\begin{tabular}{|c|c|c|c|c|c|c|c|c|c|c|c|c|}
\hline \multirow{2}{*}{ Time } & \multicolumn{2}{|l|}{ Jul } & \multicolumn{2}{|l|}{ Aug } & \multicolumn{2}{|l|}{ Sept } & \multicolumn{2}{|l|}{ Oct } & \multicolumn{2}{|l|}{ Nov } & \multicolumn{2}{|l|}{ Dec } \\
\hline & 2010 & 2011 & 2010 & 2011 & 2010 & 2011 & 2010 & 2011 & 2010 & 2011 & 2010 & 2011 \\
\hline Qualified rate (Outpatient \%) & 55.1 & 82.4 & 59.7 & 87.4 & 65.9 & 85.6 & 63.4 & 89.1 & 64.8 & 87.4 & 62.8 & 92.2 \\
\hline Qualified rate (Inpatient \%) & 43.1 & 80.5 & 45.2 & 84.9 & 44.1 & 89.9 & 45.2 & 92.1 & 44.8 & 90.1 & 46.1 & 92.3 \\
\hline
\end{tabular}

\section{Discussion}

CPMS was connected to the HIS, which could directly access the electronic medical information of patients and their prescription (medical order) information, effectively reduced the reading time of the clinical pharmacists spent on the paper medical records. Thus, the system will be able to complete the entire review of all the prescriptions in large scale hospitals [11].

Before 2011, it would take three clinical pharmacists one week to review 100 prescriptions and 30 medical orders in one month, and the quality was also unsatisfactory. Besides, when one or more specific patients, doctors, departments, 
diseases, etc. were sampled and reviewed, the workload of the clinical pharmacists would largely increase, and their manual operations were of high difficulties and errors as well On the contrary, it merely took a clinical pharmacist one week to review all the prescriptions or medical orders. Therefore, the workload of the clinical pharmacists was reduced with enhanced quality, which would effectively increase the overall work efficiency of the pharmacy department in our hospital.

Moreover, CPMS provided a variety of sampling or screening methods: parameters including time, department, doctor, diagnosis, patient name, inpatient (outpatient) number, electronic medical record, prescription evaluation and use of antibiotics could be set to inquire and screen the prescriptions or medical orders. Then the system created a prescription list, reviewed and statistically analyzed the individual prescription or medical order. Besides, when prescription samplings were required according to "Management Standards of Hospital Prescription Evaluations", any desired sampling number or sampling rates of the prescriptions could also be set in the screening interface, allowing random samplings and samplings at equal intervals [12].

Generally, CPMS was employed to evaluate the prescriptions (medical orders), which was able to timely warn and intervene the irrational prescriptions, closely contact with the clinicians, and further prevent the irrational drug use. Consequently, the procedure could be obviously optimized, leading to steady increases of the passing rates of prescriptions (medical orders) in the entire hospital. Meanwhile, taking into consideration that China's Ministry of Health launched a nationwide "Special Treatments of Antimicrobial Agents" in 2011 to address the abuse of antibiotics, another essential function was incorporated in the system that could enable the reasonable and orderly use of antibiotics [13].

General Class 1 aseptic operations, such as surface operations of heads, necks, bodies and limbs, inguinal hernia hernioplasty without artificial implants, thyroid adenoma resections and breast fibroadenoma resections, could be performed without antibiotics in most cases [14]. Antibiotics would only be allowed in major aseptic operations, long-time operations, and operations with large traumas and the high risk infections [15]. CPMS was able to monitor, track and intervene each Class 1 incision operation in time, which would thus gradually reduce the use of antibiotics in the aseptic operations in our hospital [16, 17].

The defined daily dose (DDD) of antibiotics, which has been utilized as an important index in the evaluation of excessive use of antibiotics for patients, was also included in CPMS. As a result, the DDD values of our hospital significantly reduced to those meeting the requirements of WHO $(<40)$ in a short term. Besides, the prescription (medial order) examination function for monitoring reasonable drug use was also incorporated in CPMS [18]. Retrieving the drug use information of patients aided by HIS would enable the pre-review of entire prescriptions (medical orders) and the hints of irrational drug use with their underlying reasons. Based on the statistics before and after using the system, CPMS could apparently improve the prescription levels of outpatient and inpatient doctors. Meanwhile, pharmacy information search was also incorporated in the system, which was able to accelerate the search for medicine instructions, pharmacopoeia, clinical drug use guidelines and etc. Therefore, the system not only has effectively reduced the review time of prescriptions (medical orders), but also has improved their review quality to certain extent $[19,20]$.

Furthermore, CPMS also granted diverse permission authorities for users. People with the highest authorization level in our hospital could manage all the prescriptions reviewed by the pharmacists and the submitted forms to detect the potential problems, which would finally realize the real-time management and monitoring. Meanwhile, the system was also able to statistically analyze the drug use conditions in our hospital, which would reinforce the monitoring of drug use in our hospital and provide additional support for decision making [21].

\section{Conclusions}

CPMS not only effectively promoted the scientization of drug information services in our hospital, but also performed as an essential part of information construction, which was able to fully utilize the local network of the hospital and the HIS resources, sample and screen the acquired information of patients including diagnoses and prescriptions (medical orders) to obtain electronic forms, reduce the time of manual samplings and paper medical record readings, and avoid the errors of manual operations. Therefore, irrational drug use would be monitored and reasonable references would be provided in time. The system guided daily drug use and significantly increased the work efficiency of the pharmacy department in our hospital, which would economize the medical resources, decrease the incidence of errors, facilitate the rational drug use, and eventually promote the clinical drug information services in the whole hospital onto a new level.

\section{References}

[1] FAVELA, J.; RODRIGUEZ, M.; PRECIADO, A.; GONZALEZ, V.M. Integrating context-aware public displays into a mobile hospital information system. IEEE Trans. Inf. Technol. Biomed., v. 8, n. 3, p. 279-286, 2004.

[2] GALINDO, C.; OLIVE, M.; LACASA, C.; MARTINEZ, J.; ROURE, C.; LLADO, M. et al. Pharmaceutical care: pharmacy involvement in prescribing in an acute-care hospital. Pharm. World Sci., v. 25, n. 2, p. 56-64, 2003.

[3] KIBICHO, J.; OWCZARZAK, J. A Patient-Centered Pharmacy Services Model of HIV Patient Care in Community Pharmacy Settings: A Theoretical and Empirical Framework. AIDS Patient Care STDS., v. 26, n. 1, p. 20-28, 2012.

[4] FLAHAUT, J. [Lavoisier and the Parisian pharmacists of his time]. Rev. Hist. Pharm. (Paris), v. 43, n. 308, p. 7-17, 1996. 
[5] HERNANDEZ, P.; PODCHIYSKA, T.; WEBER, S.; FERRIS, T.; LOWE H. Automated mapping of pharmacy orders from two electronic health record systems to RxNorm within the STRIDE clinical data warehouse. AMIA Annu. Symp. Proc., v. 2009, p. 244-248, 2009.

[6] GINDRE, I.; MAISONNEUVE, H.; RICHE, B.; DUROCHER, A. [Good clinical practice in using antibiotics in the hospital. Current status in 207 public and private hospitals in 1999]. Presse. Med., v. 29, n. 33, p. 1807-1812, 2000.

[7] LASSAR, T.A.; SIMON, D.I.; CROCE, K. Optimizing antiplatelet therapy following percutaneous coronary intervention: clinical pathways for platelet function testing. Rev Cardiovasc. Med., v. 12, n. Suppl 1, p. S23-33, 2011.

[8] WANG, J.; HONG, S.H.; MENG, S.; BROWN, L.M. Pharmacists' acceptable levels of compensation for MTM services: A conjoint analysis. Res. Social. Adm. Pharm., v.7, n. 4, p. 383-395, 2011.

[9] TAN, S.K.; LO, J.; ZWAHLEN, R.A. Perioperative antibiotic prophylaxis in orthognathic surgery: a systematic review and meta-analysis of clinical trials. Oral. Surg. Oral. Med. Oral. Pathol. Oral. Radiol. Endod., v. 112, n. 1, p. 19-27, 2011.

[10] CATALDO, M. A.; PETROSILlO, N. Unnecessary perioperative antibiotic prophylaxis in the placement of totally implanted central venous access ports should be avoided. Am. $J$. Surg., DOI: 10.1016/j.amjsurg.2011.02.015, 2011.

[11] CHUNG, C.; COLlins, A.; CUI, N. Development and implementation of an interdisciplinary oncology program in a community hospital. Am. J. Health. Syst. Pharm., v. 68, n. 18, p. $1740-1747,2011$.

[12] BECKER, J.H.; BAX, L.; AMER-WAHLIN, I.; OJALA, K.; VAYSSIERE, C.; WESTERHUIS, M.E. et al. ST Analysis of the Fetal Electrocardiogram in Intrapartum Fetal Monitoring: A Meta-Analysis. Obstet. Gynecol., v. 119, n. 1, p. 145-154, 2012.

[13] ARNOLD, R.S.; THOM, K.A.; SHARMA, S.; PHILLIPS, M.;
KRISTIE JOHNSON, J.; MORGAN, D.J. Emergence of Klebsiella pneumoniae carbapenemase-producing bacteria. South Med. J., v. 104, n. 1, p. 40-45, 2011.

[14] SYKES, T.A.; VENKATESH, V.; RAI, A. Explaining physicians' use of EMR systems and performance in the shakedown phase. J. Am. Med. Inform. Assoc., v. 18, n. 2, p. 125-130, 2011.

[15] VELASCO ARRIBAS, M.; RUBIO CIRILO, L.; CASAS MARTIN, A.; MARTIN SANCHEZ, M.; GAMEZ DIEZ, S.; DELGADO-IRIBARREN, A. et al. [Appropriateness of empiric antibiotic therapy in urinary tract infection in emergency room]. Rev. Clin. Esp., v. 210, n. 1, p. 11-16, 2010.

[16] JONES, D. A guiding hand for antibiotics. Nat. Rev. Drug Discov. v. 10, n. 3, p. 161-162, 2011.

[17] SURGERY BRANCH OF CHINESE ACADEMY OF MEDICAL SCIENCES, EDITORIAL BOARD OF CHINESE JOURNAL OF SURGERY. Guideline for Perioperative Antibiotic Prophylaxis. Chin. J. Surg., v. 44, n. 23, p. 1594, 2006.

[18] WESSLING, A.; BOETHIUS, G. Measurement of drug use in a defined population. Evaluation of the defined daily dose (DDD) methodology. Eur. J. Clin. Pharmacol., v. 39, n. 3, p. 207-210, 1990.

[19] WRIGHT, A.; LYTTLETON, O.; LEWIS, P.; QUIRKE, P.; TREANOR, D. The tissue microarray data exchange specification: Extending TMA DES to provide flexible scoring and incorporate virtual slides. J. Pathol. Inform., v. 2, p. 15, 2011.

[20] YANG, T.H.; KU, C.Y.; YEN, D.C.; HSIEH, W.H. Electronic Hand-Drafting and Picture Management System. J. Med. Syst., DOI: 10.1007/s10916-011-9697-y, 2011.

[21] UNERTL, K.M.; JOHNSON, K.B.; LORENZI, N.M. Health information exchange technology on the front lines of healthcare: workflow factors and patterns of use. J. Am. Med. Inform. Assoc., DOI: 10.1136/amiajnl-2011-000432, 2011. 